\title{
3 Research Square \\ Over Use of Ionisation Radiation Imaging With Paediatric Head Trauma
}

\author{
Ahmad Gharaibeh ( $\nabla$ gharaibeh@seznam.cz ) \\ University of Pavol Jozef Šafárik \\ Mahmoud Gharaibeh \\ Princes Basma Teaching Hospital \\ Ahmed Alwadiya \\ Royal Derby Hospital \\ Robert Cellar \\ Univerzitná Nemocnica Louisa Pasteura \\ Antonia Lackova \\ Univerzitná Nemocnica Louisa Pasteura \\ Vladimir Filip \\ University of Pavol Jozef Šafárik \\ Istvan Mitro \\ Univerzitná Nemocnica Louisa Pasteura \\ Marek Lacko \\ University of Pavol Jozef Šafárik
}

\section{Research Article}

Keywords: Paediatric trauma, head trauma, radiological imaging, Prevalence, Epidemiology, incidence

Posted Date: December 29th, 2020

DOI: https://doi.org/10.21203/rs.3.rs-132823/v1

License: (c) (1) This work is licensed under a Creative Commons Attribution 4.0 International License.

Read Full License 


\section{Abstract}

Purpose: Is to determinate the incidence of paediatric head trauma age 0-17 years in our region in central Europe and the number of radiographic images done for paediatric patients to make a data base for further researches, to be effective in investigating, controlling, and preventing head trauma in our population and to study the real need of radiographic images:

Methods: This is a retrospective study from the records of children with head trauma seen at the trauma clinics during the year 2018

Results: There were 3261 attendees recorded in paediatric age groups 0-17 years in 2018. 1168 paediatric patients presented with trauma to the head. 831 (36\%) with simple injuries of the head, $295(23.3 \%)$ with wounds in head area, $17(1.5 \%)$ children had fractures, $23(2 \%)$ had concussion and $2(0.2 \%)$ patients had intracranial haematoma. 1097 (93.9\%) children with head trauma were imaged by $X$ ray (1032 patients) and CT scan (65 patients) in accordance with local guidelines for head trauma management. The percentage of patients in need of radiation is only $3.42 \%$.

Conclusion: Most head trauma in children was minor and not associated with brain injury. The radiation is over used in diagnosis of paediatric head trauma

\section{Introduction}

Human skull has two major anatomical parts, neurocranium and splanchnocranium. The neurocranium is the portion of the skull that protects the brain and certain sense organs.

The splanchnocranium (or visceral skeleton) is the portion of cartilage and endochondral bone [1]. The facial skeleton is sometimes called the membranous viscerocranium, which comprises the mandible and dermatocranial elements that are not part of the braincase.

The mechanism of injury in head trauma could be due to falling down, motor vehicle accidents, sports injuries, physical fights, child abuse and playground accidents ${ }^{[2]}$.

The severity of head soft tissues injuries could be divided into abrasions, contusions, lacerations and finally avulsion injuries ${ }^{[3]}$.

Severe head trauma is less common in younger children than in adolescents and adults, because they are under adult supervision. Although falls from low heights are frequent but less injuries sustained due to their small body and low speed of the fall. These low-impact forces can usually be absorbed by their well-padded skin, elastic skeleton and cartilaginous growth centres ${ }^{[1,3]}$.

After 5-7 years of age, rapid progression of neuromotor development results in desire of independent activities especially outside home with less adult supervision ${ }^{[3]}$. 
The Craniofacial growth leads to changes in anatomy. In the first years of life, the cranium keeps up with the brains rapid pace growth and results in a relatively large and prominent forehead. Ocular globes develops quite fast early in life and join the forehead in their relative prominence. This is noticeable also in lack of paranasal sinus and in limited vertical facial height, horizontal projection, and transverse width of the maxillomandibular region. These elements result in a high skull-face ratio, making the frontal and upper orbital region more open to trauma while the lower face remains relatively protected [4].

Head injury can be closed or open also called (penetrating). A closed head injury means that a hard blow to the head from striking an object, but the object did not break the skull and sometimes causes only soft tissue injury of scalp. An open, or penetrating, head injury means you were hit with an object that broke the skull and entered the brain. This is more likely to happen when you move at high speed, such as going through the windshield during a car accident. It can also happen from a gunshot to the head ${ }^{[5]}$.

Head injuries include: Concussion, in which the brain CSF is shaken, and is the most common type of traumatic brain injury, Scalp wounds, and Skull fractures ${ }^{[5]}$.

Head injuries may cause bleeding in the brain tissue in the layers that surrounds the brain and divided into subarachnoid haemorrhage, subdural hematoma and extradural hematoma. Head injury is a common reason for an emergency room attendance. A large number of people who suffer head injuries are in fact children ${ }^{[5]}$.

\section{Materials And Methods}

This is a retrospective study of our records of children with head trauma that were seen at the trauma clinics of Teaching Hospital during the year 2018 and the authors study the number of radiographic images done for paediatric patients ( computed tomography scan (CT), X-rays). The records of 3261 patients at paediatric age groups ( $<18 \mathrm{yrs}$.) who were attending to the trauma clinics in our institute who had undergone management by surgeons or emergency doctors during the year 2018. These records were studied and analysed by excel program. All parents signed the inform consent for examination, $x$ ray or CT and the appropriate institutional forms have been archived. The authors attest that all patients participate the study had informed consent.

Purpose of the work: The main objective of our work is to determinate the incidence of paediatric head trauma in our region in central Europe and the number of radiographic images done for paediatric patients to make a data base for further researches, to be effective in investigating, controlling, and preventing head trauma in our population and to study the real need of radiographic images.

Study Location: University Hospital - UNLP SNP with 1356 beds, is the second largest Slovak hospital and provides high standards health care to patients not only from the Kosice area also in specific cases for the whole Eastern Slovakia.

Study Population: All children patients (0-17years old) with head trauma in our institute. 
Study period: From 1 January 2018 to 31 December 2018.

Data collection: The data will be collected from the records of trauma clinics of emergency teaching department and from the radiology department.

Data Analysis: Analysis of data and results was processed using statistical features of Microsoft Excel. We obtained from our hospital ethical committee, which that approved the experiment without any relevant details.

\section{Results}

A total of 3261 paediatric patients (0-17years) with trauma during the year 2018 were evaluated in our trauma clinics, SD (Standard Deviation) 654.073773 (see figure 1).

1168 paediatric patients with head trauma $35.82 \%, 831$ with simple injured of the head, 295 with wound in head area (23.3\%), 17 children had fractures, 23 paediatric patients had concussions and 2 patients had intracranial haematoma, SD 355.514838 (see figure 2)

Most of children (1097 patients, which represents 93.9\%) with blunt head trauma had radiological imaging methods such as $\mathrm{X}$ ray or computed tomography scan (CT scan) which is according to our guidelines in head trauma management in our hospital and in all Slovakia. In the age group $<4$ we found that 738 had light head trauma $89 \%$ and only 93 patients had contusion of head in the age group 4-17 years old, cut wounds 187 patients under 4 years $63 \%$ and 108 above 3 years old patients had cut wound. 17 patients had fracture in the head region 14 of them less than 4 years $82 \%, 23$ patients had concussion 8 less than 4 years $35 \%$ and 15 patients older than three years had concussion $65 \%$, finally only 2 patients had intracranial haematoma (See table No. 1) and they are above three years ( see figure No. 3). All the patients (42) with fractures, concussions and intracranial haematoma where admitted to the hospital and 4 patients with blunt head trauma and cut wound where admitted to the hospital.

\section{Table No. 1 Types of Head trauma due to age group}

\begin{tabular}{|c|c|c|c|c|c|c|c|}
\hline Age group & Light & contusion & C/W & Fracture & Concussion & Intracranial & Haematoma \\
\hline $0-3 y$ & & 738 & 187 & 14 & 8 & & 0 \\
\hline $4-17 y$ & & 93 & 108 & 3 & 15 & & 2 \\
\hline
\end{tabular}

Of the total number of patients ( $\mathrm{n}=1168), 1097$ patients underwent radiation (X-ray or CT), which represents $93.9 \%$ (see figure No 4). 1032 underwent $X$ ray imaging (at least anteroposterior and lateral views) with average ionization radiation $5 \mathrm{~m}$. Gray per patient and 65 paediatric patients underwent CT scan with average ionization radiation $20.865 \mathrm{~m}$. Gray per patient ( the hospital x ray machine is old with hard copies only). The percentage of patients in need of radiation is only $3.42 \%$ - the percentage expresses the percentage of patients classified in Fracture $(17 ; 1.45 \%)$ and Concussion $(23 ; 1.97 \%)$. 
We used the "N-1" Chi-squared test. We compared the percentage (\%) of patients who were irradiated with the percentage (\%) of patients that would need radiation. The test result showed that the number of patients who were irradiated was significantly different from the number of patients to be irradiated. X2 $(1)=1913.777, p<0.001$. The per cent difference is $90.50 \%$ with a confidence interval of $88.56 \%-92.02 \%$.

\section{Discussion}

This study analysed 1168 patients with trauma in the head region in the emergency department. $71 \%$ did not require medical care or assessment as they had no neurological deficit (Paediatric Glasgow Coma Scale is 15), but they were seen due to parental concern.

This is the first study that addresses the use of ionising radiation in the assessment of head injury (X-Ray and CT scan) among paediatric age.

A study which was done in Australia and New Zealand in 2018 on children under 18 years old in 10 trauma centres found that 20137 paediatric patients had head injuries ${ }^{[6]}$ but in this study from one trauma centre the incidence was approximately half. The Australia and New Zealand study did not investigate the use of imaging in the diagnosis of head injury.

A study on 795 children 0-15 years in Oman (2014-2015) found that $44 \%$ had head injury ${ }^{[7]}$ compared with a rate of $36 \%$ in this study.

The clinical challenge for evaluating minor head trauma in paediatric patients is to identify those infants and toddler with clinically important traumatic brain injury while limiting unnecessary radiographic imaging and radiation exposure. Neuroimaging, usually with computed tomography (CT), is highly sensitive for identifying brain injury requiring acute intervention.

The figures from this study show that most infants and children with minor head trauma can be safely discharged home after careful clinical evaluation without undergoing imaging with X-rays and/or CT scan, the percentage of patients in need of radiation is only $3.42 \%$ in this study.

However, the current guideline leads to overuse if ionising radiation. We propose that a new official guideline is introduced limiting the use of $x$-ray and CT to a defined group of patients that require it. This will allow doctors seeing and treating these patients to avoid irradiating many young patients without fear of reprisal.

\section{Conclusion}

Head trauma occurs commonly in childhood. Most head trauma in children is minor and not associated with brain injury. However, a small number of children who appear to be at low risk may have a clinically important traumatic brain injury $[2,5]$. 
The ministry of health and medical chamber (neurology and neurosurgery association) can help with reducing radiation exposure risk by reviewing current guidelines to recommend the use of $\mathrm{x}$-rays and CT only to those cases where there is significant risk of serious head injury.

The ministry of health and medical chamber must have health awareness project on radiation risk and knowledge of the initial signs required to seek medical assistance in the ER department.

\section{Declarations}

\section{Acknowledgment:}

We thank the staff of Emergency and radiology departments and our colleagues in our institution who help us in this study.

\section{Conflict of Interest Statement:}

All authors declared that the research was conducted in the absence of any commercial or financial relationship that could be construed as a potential conflict of interest. All other authors have no competing/conflict of interest.

contribution statement: The authors confirm contribution to the paper as follows: study conception and and objectives of paper: Gharaibeh Ahmad, Garaibeh Mahmoud M; data collection: Gharaibeh Ahmad, Cellar Robert, Lackova Antonia; elaborate, analysis and interpretation of data: Gharaibeh Ahmad, Garaibeh Mahmoud M., Alwadiya Ahmed; draft manuscript preparation: Gharaibeh Ahmad, Garaibeh Mahmou M., Alwadiya Ahmed, Lackova Antonia, Filip Vladimir; statistical analysis: Gharaibeh Ahmad, Alwadiya Ahmed, Cellar Robert, Filip Vladimir; working out the literature: Gharaibeh Ahmad, Garaibeh Mahmoud M., Mitro Istvan, Lacko Marek; obtaining fund: Lacko Marek; All authors reviewed the results and approved the final version of the manuscript.

\section{Funding:}

The work was supported by the Scientific Grant Agency of the Ministry of Education, Science, Research and Sports of the Slovak Republic - VEGA no.1/0598/20.

Declarations: I confirm that all methods were carried out in accordance with relevant guidelines and regulations.

We confirm that:

a) All methods were carried out in accordance with relevant guidelines and regulations.

b) The study was reviewed, considered and approved by the Ethics Committee of the University hospital of L. Pasteur. 
c) All experimental protocols were approved by the Ethics Committee of the University Hospital of L. Pasteur.

d) All necessary patient/participant consent has been obtained and the appropriate institutional forms have been archived.

\section{References}

1. Kent, George C.; Carr, Robert K. Comparative Anatomy of the Vertebrates, New York, NY: McGraw-Hill, 9, (2001)

2. Astrand R, Romner B. Classification of Head Injury. Management of Severe Traumatic Brain Injury, Springer Berlin Heidelberg, 11-16, (2012)

3. Wan Dinah, Small Kevin H., Barton Fritz E. Face lift. Plastic and Reconstructive Surgery. 136, 5, 676689 (2015)

4. Bedell Gary, Coster Wendy. Measuring Participation of School-Aged Children with Traumatic Brain Injuries: Considerations and Approaches. Journal of Head Trauma Rehabilitation, 23, 4, 220-229 (2008)

5. George A Alexiou, George Sfakianos, Neofytos Prodromou. Pediatric head trauma. J Emerg Trauma Shock, 4(3): 403-408 (2011)

6. Babl FE, Pfeiffer H, Dalziel SR, Oakley E, Anderson V, Borland ML, Phillips N, Kochar A, Dalton S, Cheek JA, Gilhotra Y, Furyk J, Neutze J, Lyttle MD, Bressan S, Donath S, Hearps SJ, Crowe L.

Paediatric intentional head injuries in the emergency department: A multicentre prospective cohort study., (2018)

7. Amber Mehmood, Priyanka Agrawal, Katharine A Allen, Ammar Al-Kashmiri, Ali Al-Busaidi, Adnan Ali Hyder. Childhood injuries in Oman: retrospective review of a multicentre trauma registry data. BMJ Paediatr Open, 2(1) (2018)

\section{Figures}




\section{Paediatric Trauma 2018}

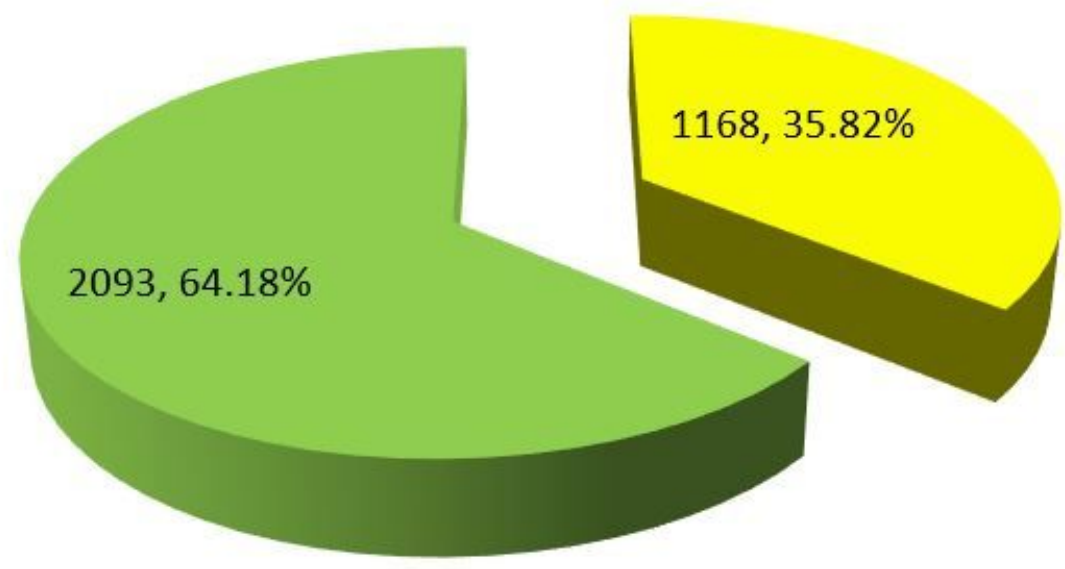

Pediatric head trauma

Rest pediatric trauma

\section{Figure 1}

Head trauma incidence

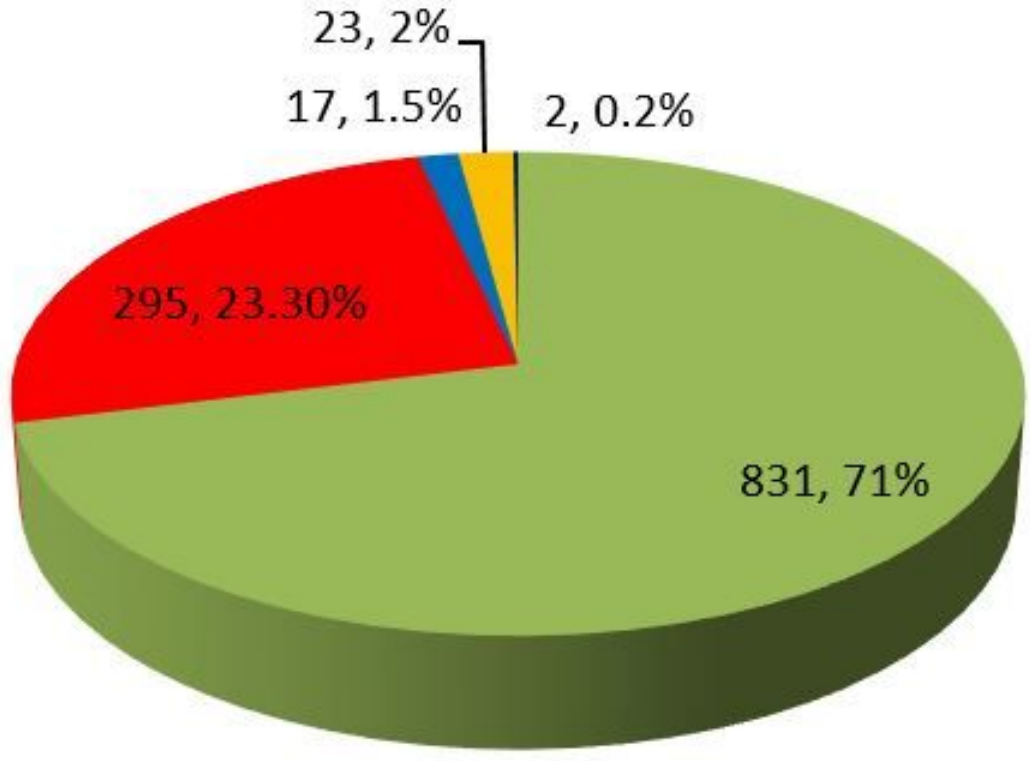

Blunt trauma without fracture

Cute wound

- Fracture

Concussion

Intracranial Heamatoma 
Figure 2

Head trauma incidence due to severity

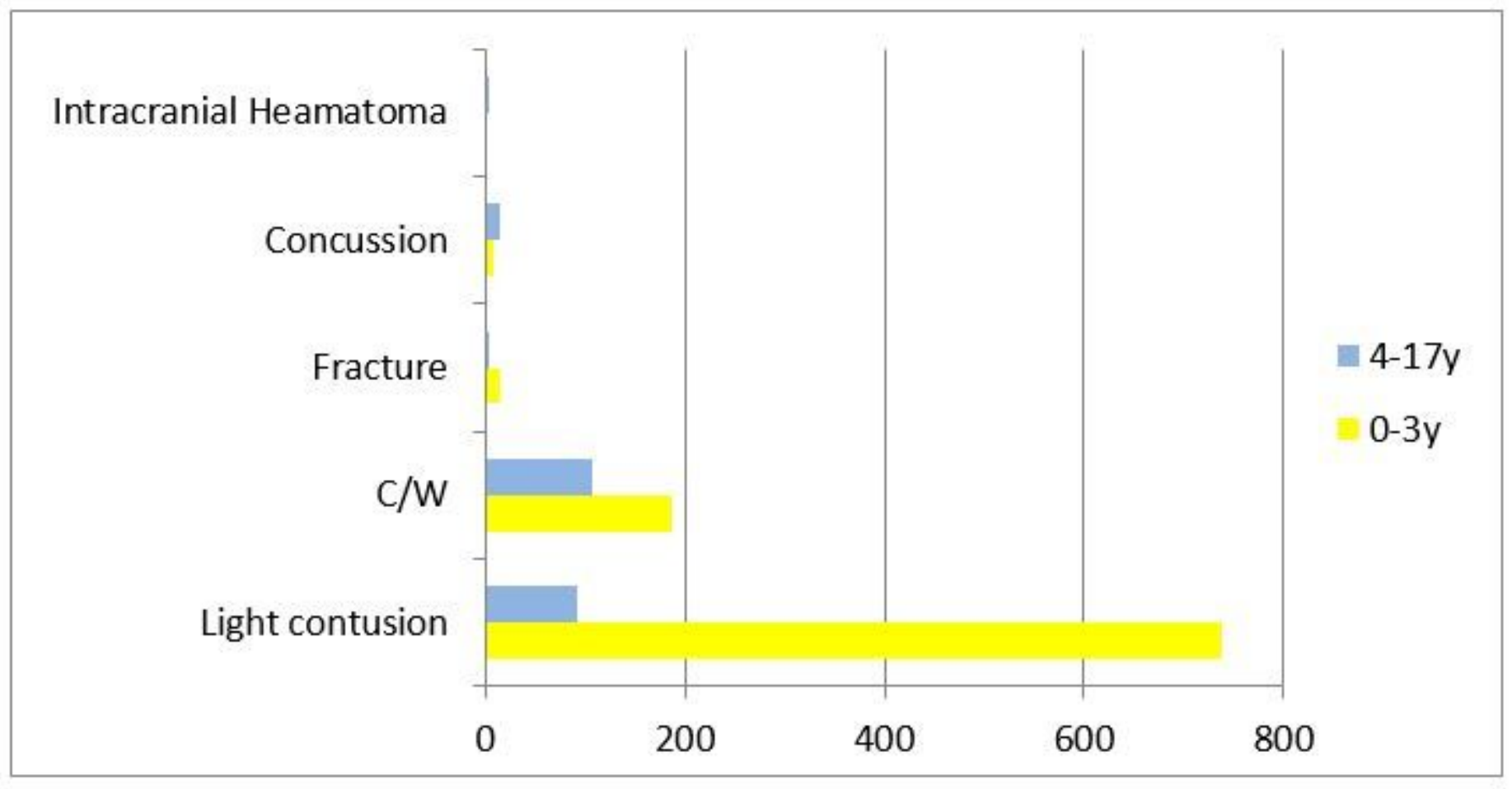

Figure 3

Head trauma incidence due to age 


\section{Number of imiging}

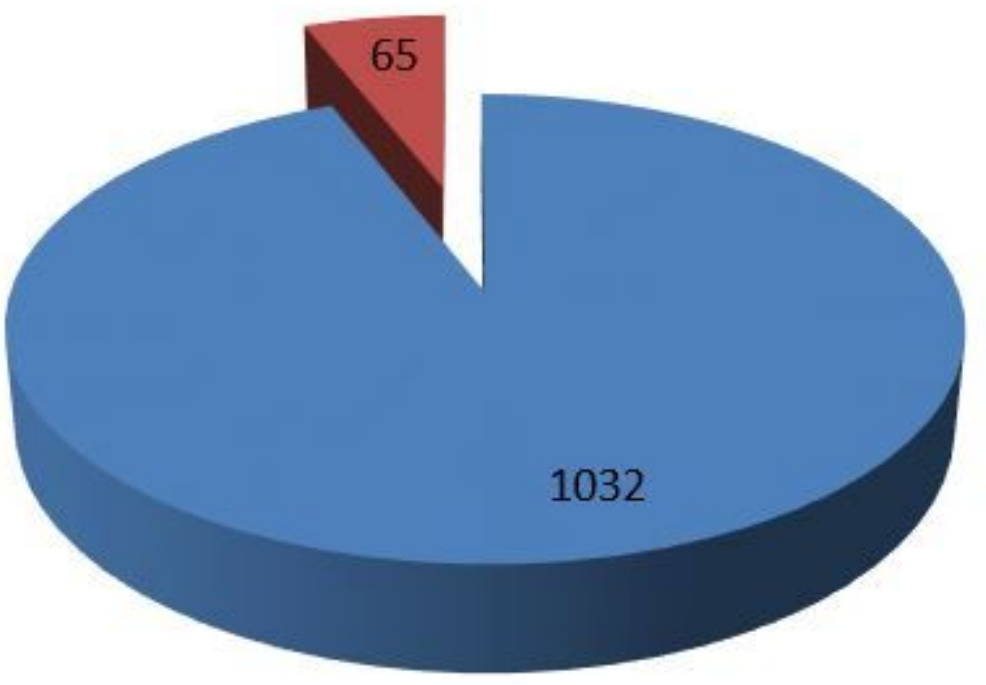

X-Ray

- CT scan

Figure 4

Number of imaging of Head trauma due to type 